\title{
Cleavage Stress Producing Notch-Induced Anisotropic Fracture and Crack Path Deflection in Cold Drawn Pearlitic Steel
}

\author{
Jesús Toribio * and Francisco-Javier Ayaso
}

check for updates

Citation: Toribio, J.; Ayaso, F.-J.

Cleavage Stress Producing

Notch-Induced Anisotropic Fracture and Crack Path Deflection in Cold

Drawn Pearlitic Steel. Metals 2021, 11, 451. https://doi.org/10.3390/ met11030451

Academic Editor: Ludmila Kučerová

Received: 31 December 2020

Accepted: 28 February 2021

Published: 9 March 2021

Publisher's Note: MDPI stays neutral with regard to jurisdictional claims in published maps and institutional affiliations.

Copyright: (c) 2021 by the authors. Licensee MDPI, Basel, Switzerland. This article is an open access article distributed under the terms and conditions of the Creative Commons Attribution (CC BY) license (https:/ / creativecommons.org/licenses/by/ $4.0 /)$.
Fracture \& Structural Integrity Research Group (FSIRG), University of Salamanca (USAL), EPS, Campus Viriato, Avda. Requejo 33, 49022 Zamora, Spain; fja@usal.es

* Correspondence: toribio@usal.es; Tel.: +34-677-56-67-23

\begin{abstract}
The fracture performance of axisymmetric notched samples taken from pearlitic steels with different levels of cold-drawing is studied. To this end, a real manufacture chain was stopped in the course of the process (on-site in the factory), and samples of all intermediate stages were extracted from the initial hot-rolled bar (not cold-drawn at all) to the final commercial product (prestressing steel wire). Thus, the drawing intensity or straining level (represented by the yield strength) is treated as the key variable to elucidate the consequences of manufacturing on the posterior fracture issues. On the basis of a materials science approach, the clearly anisotropic fracture behavior of heavily drawn steels (exhibiting deflection in the fracture surface) is rationalized on the basis of the markedly oriented pearlitic microstructure of the cold-drawn steel that influences the operative micromechanism of fracture. In addition, a finite element analysis of the stress distribution at the fracture instant allows the computation of the cleavage annular stress required to produce anisotropic fracture behavior and thus crack path deflection associated with mixed-mode cracking. Results show that such a stress is the variable governing initiation and propagation of anisotropic fracture by cleavage (a specially oriented and enlarged cleavage fracture) appearing along the wire axis direction in the case of sharply-notched samples of heavily drawn pearlitic steels.
\end{abstract}

Keywords: cleavage stress; notch tensile strength; anisotropic fracture; crack path deflection; colddrawn pearlitic steel

\section{Introduction}

Cold-drawn pearlitic steel $[1,2]$ is a structural material widely used in wire form as a component of prestressed concrete structures in civil engineering. The manufacture process to produce cold-drawn pearlitic steel wires is made by progressive plastic deformation from the initial hot-rolled bar (free of plastic strain because it is not cold-drawn at all) to the final commercial product (prestressing steel wire that has undergone a heavy drawing route). From the point of view of mechanical behavior of the material, the cold-drawing process generates an increase of yield stress and ultimate tensile strength of the steel by means of a strain hardening mechanism.

High-strength cold-drawn eutectoid pearlitic steel wires, called prestressing steel wires in structural engineering [2], can be considered as high-performance materials [2] because they have an extremely high tensile strength only limited by cleavage fracture (the so-called cleavage limited strength), cf. [3] and react in a non-conventional manner due to their inherent anisotropy induced by the manufacture process in the form of multi-step (progressive) cold-drawing. This anisotropy is related to yielding and plastic behavior (anisotropic plastic behavior), as reported by Toribio [2], and also linked with fatigue and fracture performance (anisotropic fracture behavior), as described elsewhere [4-6] with the result of mixed-mode fracture propagation and strength anisotropy. With regard to the fractography associated with the aforesaid anisotropic behavior, a special type of cleavage has been described by Toribio and Ayaso [7], and the concept of exfoliation fracture has been used [7] as well as the idea of delamination cracks [8]. 
With regard to microstructural evolution, one can distinguish between the classical studies [9-11] and more recent ones [2,12,13]. The cold-drawing process produces a progressive orientation of the pearlite colony (first microstructural level) with its main axis approaching the axis of the wire or cold-drawing direction, and a slenderizing of the colony itself, cf. [2]. In the matter of the pearlitic lamellar microstructure or second microstructural level, cold-drawing produces both a decrease of interlamellar spacing and an orientation of the plates in the cold-drawing direction, cf. [2].

The consequence of the aforesaid microstructural arrangement is the anisotropic fracture behavior of the cold-drawn pearlitic steels. In this paper, a combined (fractographic and numerical) analysis is performed on the consequences of the aforesaid microstructural arrangement in the progressively drawn pearlitic steel wires, manifested in the form of a markedly anisotropic fracture behavior of the most heavily drawn wires. The fractographic study allows an analysis of the situations in which the anisotropic behavior takes place, whereas the numerical analysis gives the stress distribution responsible (in conjunction with the microstructural orientation) for the crack path deflection in the cold-drawn wires, so as to elucidate the important role of the hoop stress (cleavage annular stress) in promoting the anisotropic fracture.

\section{Experimental Program}

\subsection{Materials Used}

The materials used in the fracture tests were eutectoid steel wires with different levels of cold-drawing (i.e., distinct degrees of accumulated plastic strain), from the initial hotrolled bar (not cold-drawn at all) to the final commercial product (prestressing steel wire; heavily cold-drawn at a drawing speed of $5 \mathrm{~m} / \mathrm{s}$ during the final pass). Table 1 shows the chemical composition of the steel (valid for any drawing degree). Table 2 indicates the dimensions of the wires and the mechanical properties of the different steel wires. The materials were named with the letter $\mathrm{A}$ and the numbers 0 to 6 , and this number indicates the number of cold-drawing stages undergone by each wire (thus the steel A0 represents the initial hot-rolled bar and the steel A6 the final commercial product or prestressing steel wire).

Table 1. Chemical composition of the steel ( $w \mathrm{t} \%$; the balance is $\mathrm{Fe}$ ).

\begin{tabular}{cccccccc}
\hline $\mathbf{C}$ & $\mathbf{M n}$ & $\mathbf{S i}$ & $\mathbf{P}$ & $\mathbf{S}$ & $\mathbf{A l}$ & $\mathbf{C r}$ & $\mathbf{V}$ \\
\hline 0.80 & 0.69 & 0.23 & 0.012 & 0.009 & 0.004 & 0.265 & 0.06 \\
\hline
\end{tabular}

Table 2. Wire dimensions and mechanical properties of the steel wires.

\begin{tabular}{ccccccc}
\hline Steel & $\mathbf{D}(\mathbf{m m})$ & $\mathbf{D i} / \mathbf{D 0}$ & $\boldsymbol{\varepsilon}^{\boldsymbol{P}_{\text {cum }}}$ & $\mathbf{E}(\mathrm{GPa})$ & $\boldsymbol{\sigma} \mathbf{Y}(\mathrm{GPa})$ & $\boldsymbol{\sigma R}(\mathrm{GPa})$ \\
\hline A0 & 12.00 & 1 & 0 & 197.4 & 0.686 & 1.175 \\
A1 & 10.80 & 0.9 & 0.21 & 201.4 & 1.100 & 1.294 \\
A2 & 9.75 & 0.82 & 0.42 & 203.5 & 1.157 & 1.347 \\
A3 & 8.90 & 0.74 & 0.60 & 197.3 & 1.212 & 1.509 \\
A4 & 8.15 & 0.68 & 0.77 & 196.7 & 1.239 & 1.521 \\
A5 & 7.50 & 0.63 & 0.94 & 202.4 & 1.271 & 1.526 \\
A6 & 7.00 & 0.58 & 1.08 & 198.8 & 1.506 & 1.762 \\
\hline
\end{tabular}

From a macroscopic point of view, the cold-drawing process shows a progressive decrease of wire diameter and a progressive increase of length (the cumulative plastic strain during drawing can be calculated as $\varepsilon^{p_{c u m}}=\ln \left(D_{0} / D_{i}\right)^{2}$, where $D_{i}$ is the diameter in a particular wire and $\mathrm{D}_{0}$ the initial diameter before cold-drawing).

From a microscopic viewpoint, a clear evolution in the disposition of the pearlite colonies and lamellae is observed after grinding, polishing, and etching with Nital to perform the metallographic analysis. In Figure 1a, a longitudinal metallographic section of steel 0 (initial hot-rolled steel) is showed. It is possible to observe different pearlitic 
colonies whose orientation is not well defined, i.e., the colonies are randomly oriented. As the plastic strain induced by the cold-drawing process becomes higher, one can observe that pearlitic colonies and lamellae are progressively oriented in a direction close to the cold-drawing one (the wire axis). The greater the cumulative plastic strain induced by the cold-drawing process, the more pronounced the global orientation of the pearlitic colonies along the wire axis. In Figure 1b, a longitudinal section of steel 6 (high plastic strain level) is represented, it being possible to observe the direction of pearlite colonies (ferritic and cementite lamellae too) aligned very close to the wire axis.

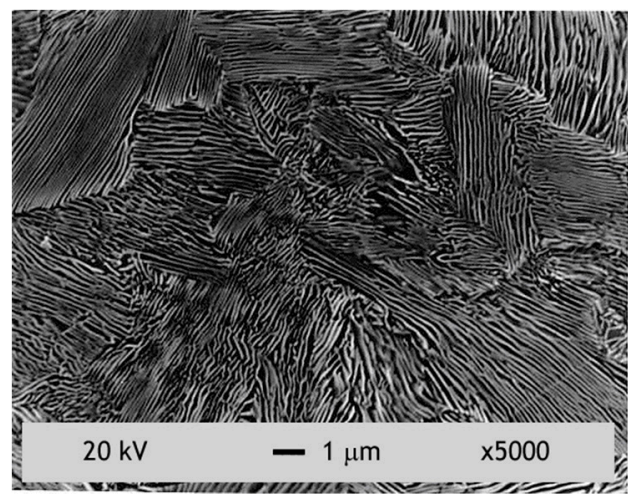

(a)

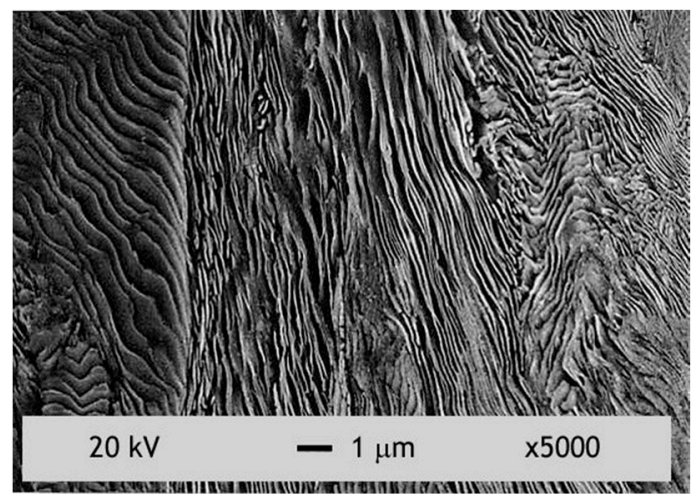

(b)

Figure 1. Longitudinal metallographic sections of hot-rolled pearlitic steel 0 (a) and cold-drawn pearlitic steel 6 (b). In both cases, the vertical side of the micrographs corresponds to the wire axis or cold-drawing direction.

Figure 2 plots the stress-strain curves for the progressively cold-drawn pearlitic steels from A0 (hot-rolled steel, 0 drawing steps) to the commercial prestressing steel wire A6 (heavily cold-drawn pearlitic steel undergoing 6 drawing steps). It is seen that both the yield strength $\sigma_{Y}$ and the ultimate tensile strength (UTS $\sigma_{\max }$ ) increase with the drawing degree, cf. [2]. Curves A1 to A5 (medium drawing degree) are shorter due to surface and local curvature imperfections, whereas curve A6 is longer and different after stress relieving treatment to obtain the final commercial product (prestressing steel).

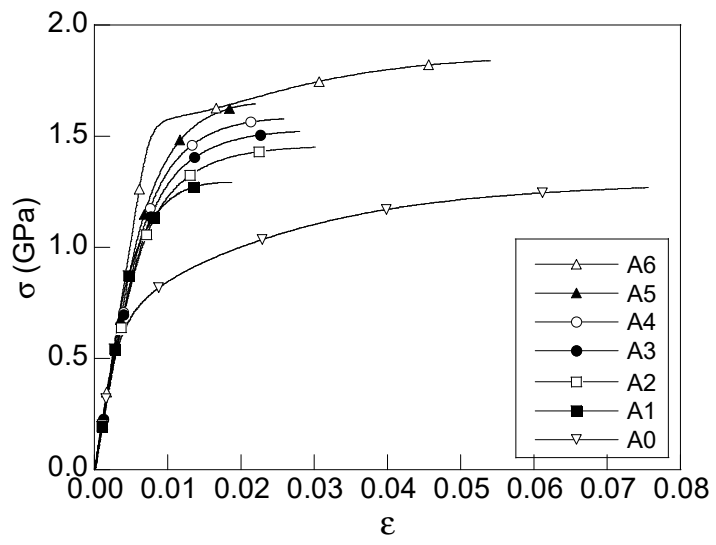

Figure 2. Stress-strain curves of the progressively drawn pearlitic steels A0 to A6 (from 0 to 6 colddrawing steps).

With regard to the materials science relationship between microstructure and strength, the Hall-Petch equation [14,15] has been proposed by Choi and Park [16] and Nam et al. [17] to correlate the pearlite interlamellar spacing and the material strength. Although the HallPetch equation seems to be effective to describe the relationship between microstructure and strength in randomly oriented pearlitic microstructures, it does not properly work for drawn pearlite, i.e., for the case of oriented pearlitic microstructures, as reported by 
Toribio [18]. However, for cold-drawn pearlite oriented in a direction quasi-parallel to the wire axis or cold-drawing direction, an Embury-Fisher equation [9] has been proposed by Toribio et al. [19] to describe the proper relationship between microstructure and strength in cold-drawn pearlitic steels.

\subsection{Types of Samples}

Axisymmetric notched samples were used. The notched geometries are showed in Figure 3. Each one of the notches was machined in the different wires keeping constant the ratios $C / D$ and $R / D$ for all plastic strain degrees, $C$ being the notch depth, $R$ the notch radius, and $\mathrm{D}$ the nominal diameter of the steel. The dimensions of the specimens (named $\mathrm{A}, \mathrm{B}, \mathrm{C}$, and $\mathrm{D}$ throughout this paper) were the following:

Geometry A: R/D $=0.03, C / D=0.10$

Geometry B: R/D $=0.05, C / D=0.30$

Geometry $C: R / D=0.40, C / D=0.10$

Geometry $\mathrm{D}: \mathrm{R} / \mathrm{D}=0.40, \mathrm{C} / \mathrm{D}=0.30$

In the described geometries, $\mathrm{R}$ is the notch radius, $\mathrm{C}$ the notch depth, and $\mathrm{D}$ the external diameter of the axisymmetric specimen.

For clarity and simplicity, the samples were named following the next rule: each sample was named with a number followed by a capital letter; the number relates to the cold-drawing steps undergone by the steel and the letter indicates the notch type in the wire. For example: consider a sample labelled $4 \mathrm{C}$, this label indicates that the sample comes from a wire obtained after 4 drawing passes and that this sample has a notch type $C$ (high notch tip radius and small notch depth in the wire).

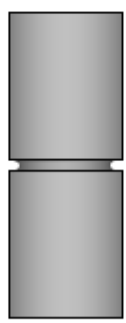

(A)

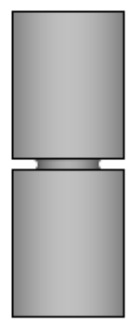

(B)

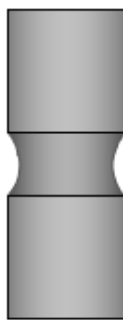

(C)

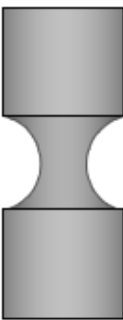

(D)

Figure 3. Scheme of axisymmetric notched specimens A, B, C, and D.

\subsection{Fracture Tests and Fractographic Analysis}

Each one of the notched samples was tested until fracture by means of a fracture test in axial direction using a servo-hydraulic universal testing machine (INSTRON mod. 8516, Instron, High Wycombe, UK) and one extensometer (INSTRON, mod. 2620.602, Instron, High Wycombe, UK) with an original gauge length of $25 \mathrm{~mm}$. For each geometry (four geometries) and plastic strain degree (seven degrees), three tests were carried out. The details of the tests are described elsewhere [4]. With regard to the fractographic analysis performed by scanning electron microscopy SEM (JEOL, mod. JSM-6400, Tokyo, Japan), both the micro-mechanism of fracture and the fracture process zone (FPZ) are functions of the plastic strain degree and the notch geometry, cf. [4].

In this paper, the study is focused in the markedly anisotropic fracture behavior that exhibits heavily drawn steels. Firstly, two main groups may be distinguished: one formed by the steels with moderately low plastic strain (cold-drawing steps 0,1 , and 2) where the fracture surface is contained in the transverse net section (located at the deepest point of each notch), see Figure 4 . The other main group is formed by the steels that have undergone severe plastic deformation and a higher cold-drawing degree (steels 3, 4, 5, and 6). In this latter group, two behaviors may be observed: on one hand, the steels with a cold-drawing degree $\geq 3$ and with a notch type $A$ and $B$ show a fracture surface containing deflection 
planes and thus exhibiting anisotropic fracture behavior (Figures 5 and 6). On the other hand, the steels with a cold-drawing degree $\geq 3$ too, but in this case, with a notch type $C$ and $\mathrm{D}$, do not show such anisotropic fracture behavior, but the whole fracture surface is contained on the transverse net section of the wire (Figure 7).

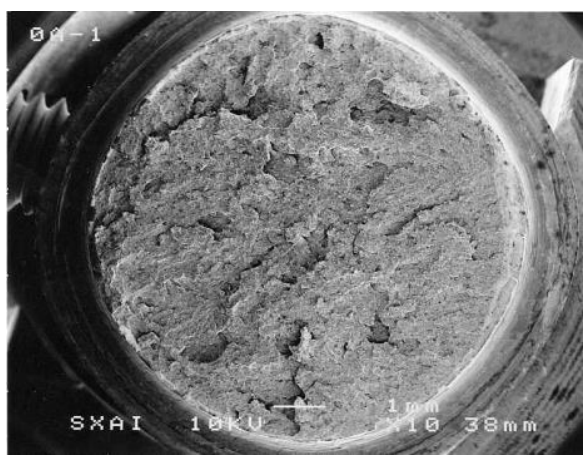

(a)

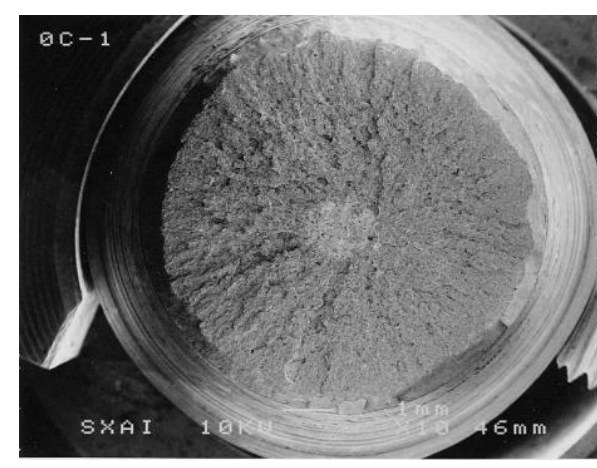

(b)

Figure 4. Sample $0 \mathrm{~A}(\mathbf{a})$ and $0 \mathrm{C}(\mathbf{b})$ : isotropic fracture behavior.

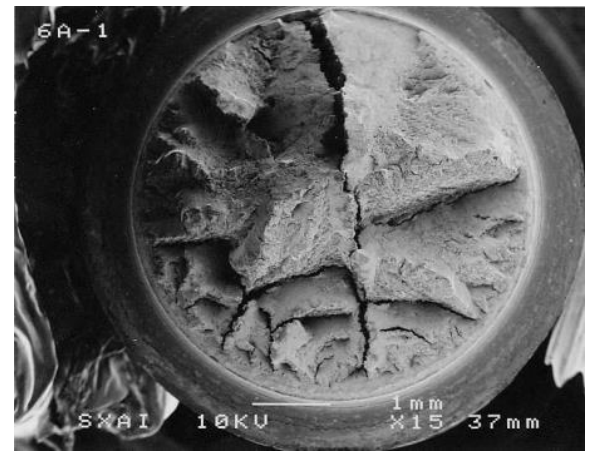

(a)

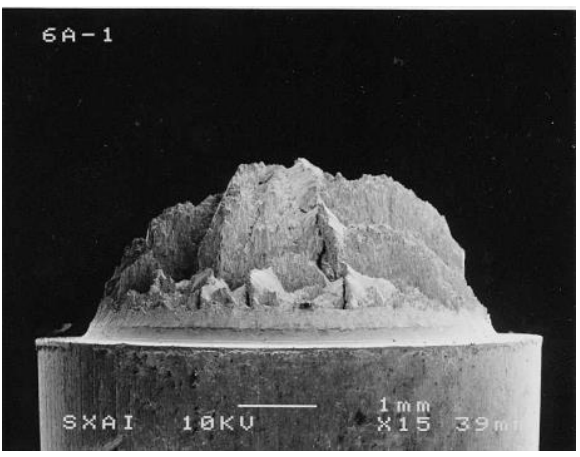

(b)

Figure 5. Sample 6A with anisotropic fracture behavior: front view (a) and side view (b).

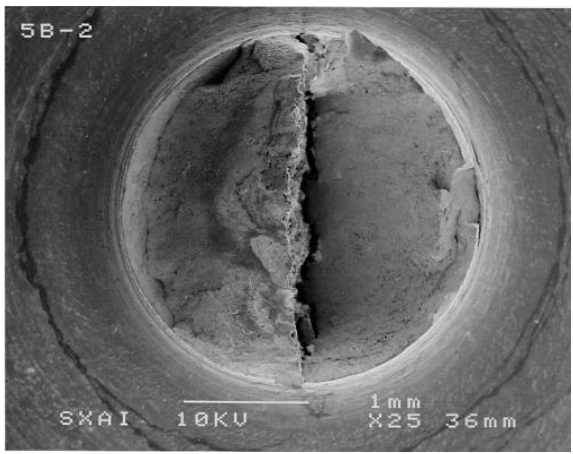

(a)

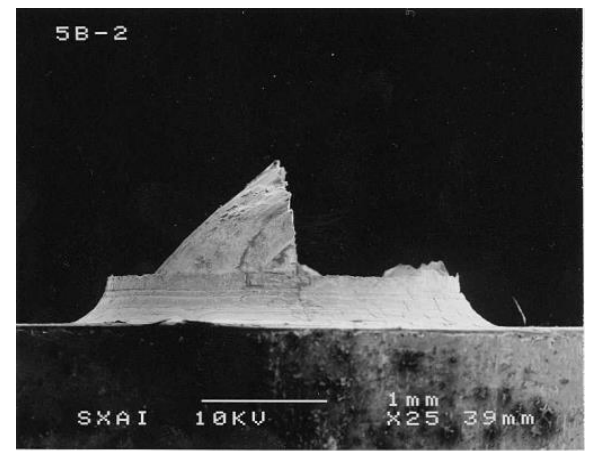

(b)

Figure 6. Sample 5B with anisotropic fracture behavior: front view (a) and side view (b). 


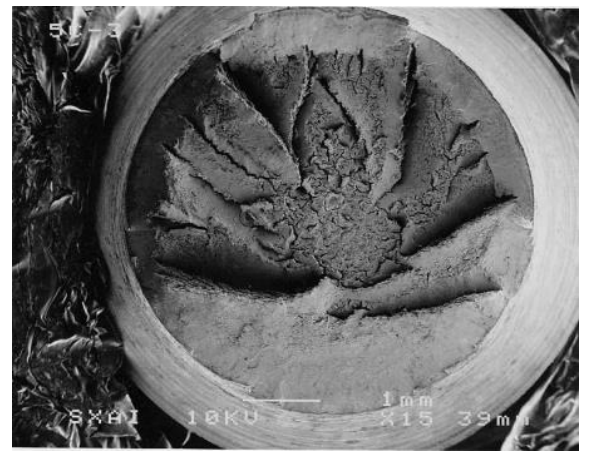

(a)

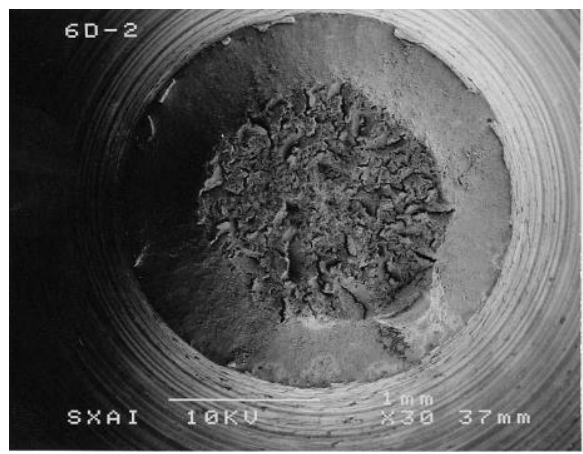

(b)

Figure 7. Sample 5C (a) and 6D (b): isotropic fracture behavior.

\subsection{Computation of Internal Variables}

The finite element method (FEM) using a commercial MSC-MARC code was used to perform a simulation and analysis of the loading-straining process in each tested sample for every cold-drawing degree and notch geometry, and using the constitutive relationships provided by the stress-strain curves given in Figure 2 for each steel wire. The external load was applied step by step, using a Von Mises yield surface, in the form of nodal displacements. An improved Newton-Raphson method was adopted, which modified the tangent stiffness matrix at each step. Large strains and large geometry changes were used in the computations by means of an updated Lagrangian formulation to predict the distribution of mechanical variables in the samples for the instant of final failure by physical separation of the two fracture surfaces.

The constitutive equation of the material—as a relationship between equivalent stress and strain -was introduced into the computer program from the real experimental results of the standard tension tests of the considered materials (cf. Figure 2). The curves were extended for large strains based on the volume conservation in classical plasticity and accounting for the strain hardening evolution to obtain steel 6 from the previous materials (steel wires A0 to A5). The finite elements used in the computations were isoparametric with second-order interpolation (eight-node quadrilaterals). The number of mesh elements, in the area near the notch, is 432 for the case of notch A, 180 for notch type B, and 196 for the notches type $C$ and $D$.

As a consequence of the different notched geometries, very distinct triaxiality stress states are obtained in the net section of the wires. This state of stress triaxiality is very different to that obtained during the standard fracture test (uniaxial stress state). In this point, it is interesting to know the stress distribution along the net section of the different samples (function of the cold-drawing degree and notch geometry).

In Figure 8, a scheme of a notched sample and a detail of its net section are represented. During the fracture test, an increasing load F was applied on the notched sample until a fracture occurred. The load F created a triaxial stress state at the notch tip and its vicinity: the axial or normal tension $\sigma_{Z}$ (in the same direction that the axis of load application), the radial stress $\sigma_{r}$, and the hoop stress $\sigma_{\theta}$. The values of the stress components $\sigma_{r}, \sigma_{\theta}$, and $\sigma_{z}$ in the net section of each wire were different along the net radius (the radius of the wire in the net section) as well as throughout the loading process. The stress study presented in this paper corresponds exactly to the instant previous to the final fracture by means of total separation of specimen surfaces. 


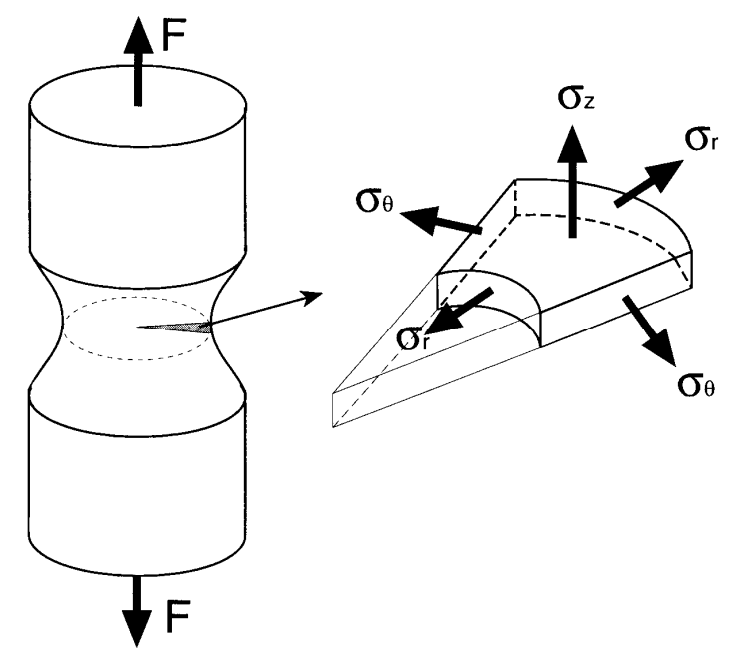

Figure 8. Scheme representing the stress distribution in the net section of the notched wires.

\section{Numerical Results}

By means of the finite element method (FEM), different internal variables were obtained during the whole tensile loading process (and particularly at the fracture instant). Among others, the variables more interesting for this purpose are the hydrostatic stress, the effective or equivalent Von Mises Stress, the equivalent plastic strain, and the components of the stress tensor (in particular the hoop stress) that allowed one to know their distribution on the net section of each sample.

Therefore, the stresses $\sigma_{\mathrm{r}}, \sigma_{\theta}$, and $\sigma_{\mathrm{z}}$ acting on the net section of each tested wire were numerically obtained by the finite element method, with special attention to the value and distribution of the hoop stress $\sigma_{\theta}$ along the net wire radius just at the fracture instant. Moreover, these variables permit one to establish a fracture criterion as a function of the distortional component of the strain density in agreement with a critical value of the Von Mises effective (equivalent) stress.

The work presented in this paper analyzes the stress distribution $\left(\sigma_{\mathrm{r}}, \sigma_{\theta}\right.$, and $\left.\sigma_{\mathrm{z}}\right)$ that occurs in the net section on the wires just in the moment before fracture happens. Attention is paid to the value and distribution (along the net radius) of the hoop stress $\sigma_{\theta}$, which in principle is responsible for the fracture deflection path in some steels. This deflection path is a function of the plastic strain degree (cold-drawing step $\geq 3$ ) and notch geometry (notches type $\mathrm{A}$ and $\mathrm{B}$ : with a common small notch tip radius).

With regard to the hoop stress distribution along the net radius of the wires, it can be observed that each notch has a particular distribution of the hoop stress for each notch type. This stress distribution is independent of the plastic strain degree. In this way, two similar behaviors can be found: one for the wires with small radius notches (notches type A and B) and in the other hand, the wires with high notch tip radius (notches type $C$ and D).

Figure 9 shows the dimensions of the notched geometries. Figures 10-12 plot the hoop stress $\sigma_{\theta}$ for the initial hot-rolled bar (steel A0), for a steel with an intermediate accumulated plastic strain degree (steel A3), and for the final commercial product (steel A6). In these graphs, the different notches for each wire are represented, where $x$ is the distance from the bottom of each notch to the longitudinal axis of the wire (cf. Figure 9). 


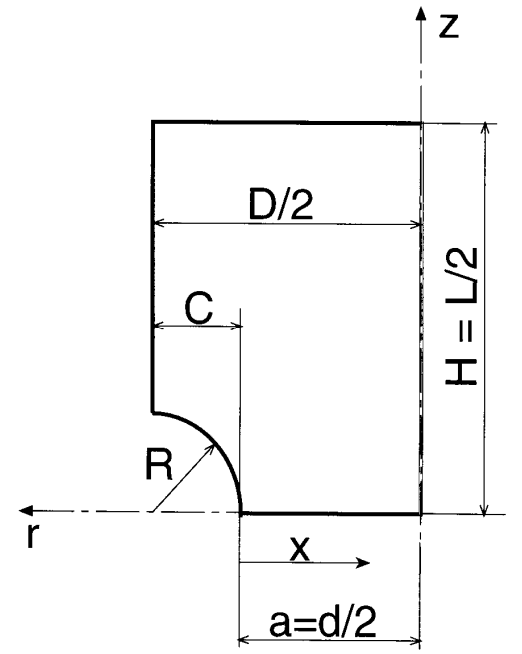

Figure 9. Dimensions of the notched geometries.

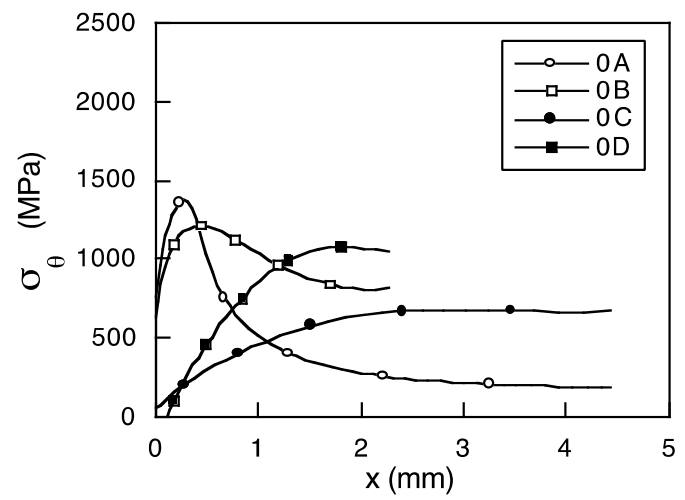

Figure 10. Distribution of hoop stress in notched samples of steel A0.

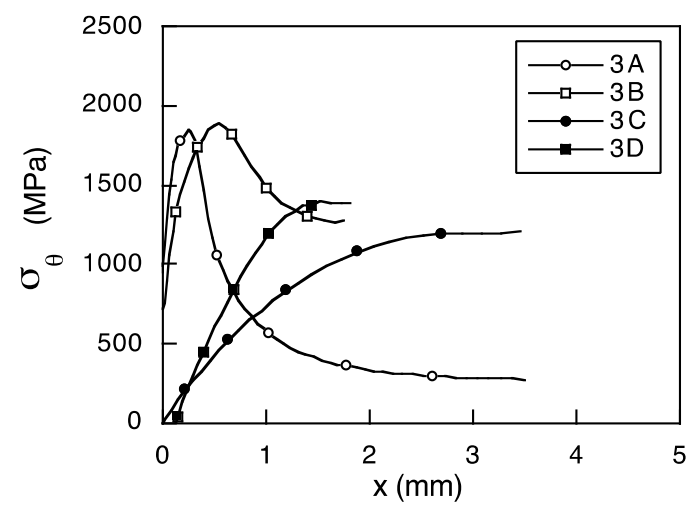

Figure 11. Distribution of hoop stress in notched samples of steel A3. 


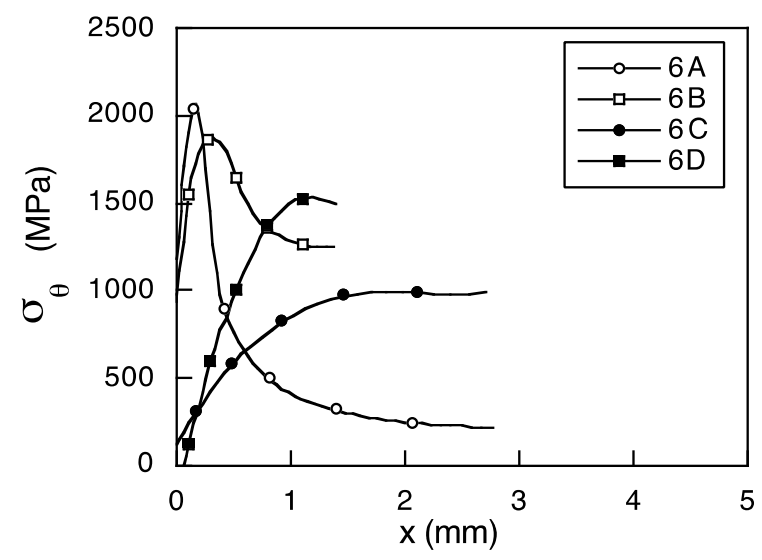

Figure 12. Distribution of hoop stress in notched samples of steel A6.

The wires (samples) with small notch geometry radius (sharp notches A and B) show an increasing hoop stress in the zone near to the bottom of the notch. In this zone, the hoop stress increases sharply up to its maximum value. Once in this maximum point, the hoop stress distribution shows a progressive decrease down to the longitudinal wire axis. With regard to the value of the hoop stress, it can be observed that $\sigma_{\theta}$ increases gradually with the cold-drawing degree in all its distribution along the wire's radius, reaching the maximum values in the wires with sharp notches type $A$ and $B$ (small notch radius). This behavior is observed with independence of the considered cold-drawing degree.

With regard to those samples with a blunt notch geometry type $C$ and $D$ (high notch radius), it can be observed that the value of hoop stress is zero in the bottom of the notch $(x=0)$, and presents a progressive increasing of $\sigma_{\theta}$ up to the longitudinal wire axis. In this point (the longitudinal wire axis), the maximum value of the hoop stress concentration can be found for the wires with these types of blunt notches, the higher value being for the D notch.

Figure 13 shows the evolution on maximum values that presents the hoop stress $\sigma_{\theta}$ for all cold-drawing degrees and notch types studied in this work. This plot shows that the maximum values in the hoop stress $\sigma_{\theta \max }$ are for the specimens with small notch radius (sharp geometries A and B) in independence of the considered cold-drawing degree. The minimum values of the hoop stress are for those samples with high notch radius (blunt geometries $\mathrm{C}$ and $\mathrm{D})$.

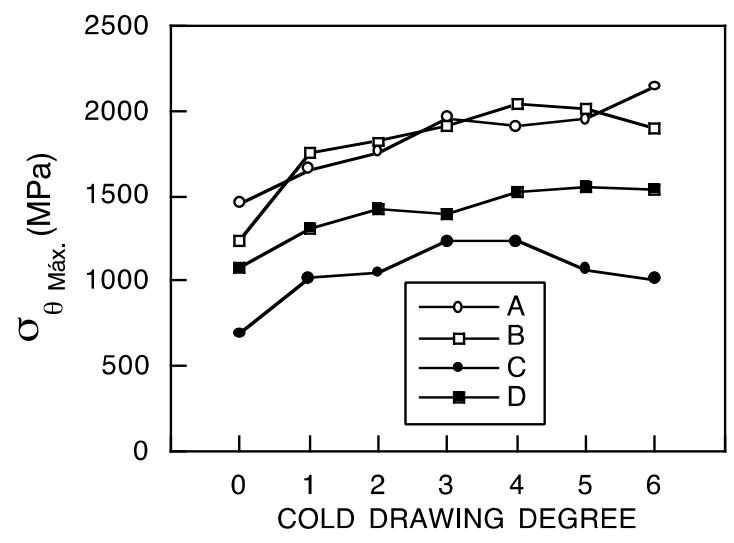

Figure 13. Maximum values of hoop stress.

\section{Discussion: Micromechanical Model}

In this point, a micro-mechanical model (Figure 14) is proposed to explain the existence of the fracture deflection path in steels with high cumulative plastic strain (cold-drawing degree $\geq 3$ ) as a function of the triaxiality factor $\mathrm{T}$ (maximum value of the triaxiality in the 
net section of the wires). With regard to the triaxiality factor $\mathrm{T}$, samples with sharp notches type $\mathrm{A}$ and $\mathrm{B}$ present the maximum value of $\mathrm{T}$ due to the high level of constraint in these notches (with small notch radius).

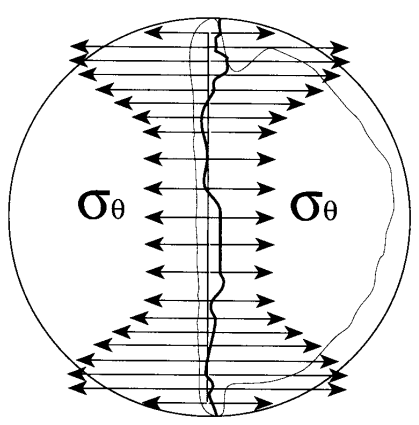

$\Downarrow$

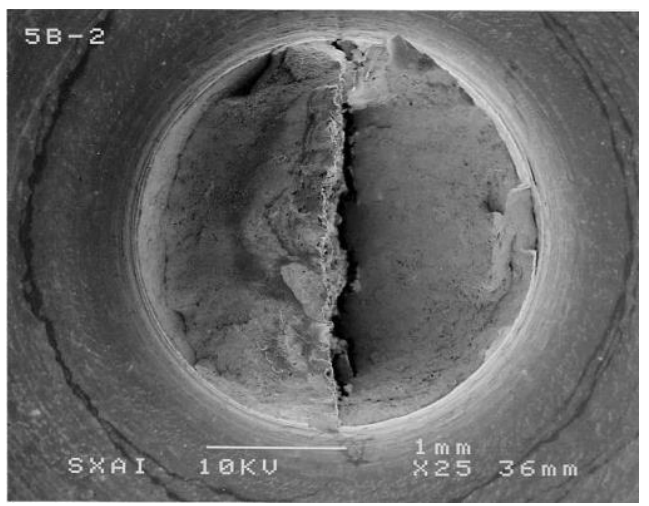

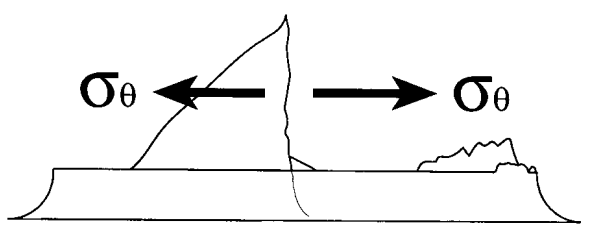

$\Downarrow$

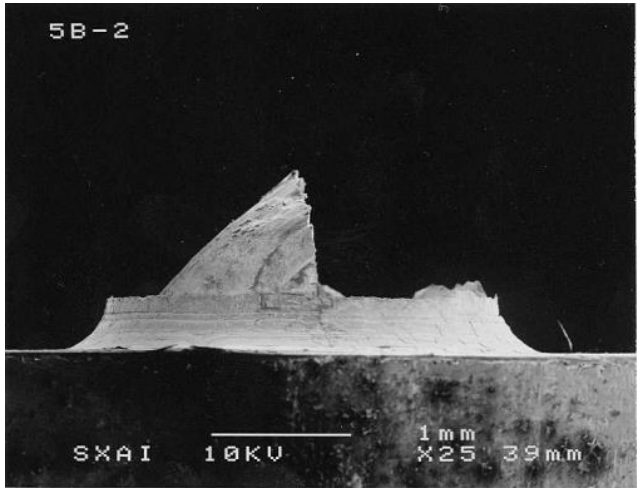

Figure 14. Distribution of the hoop stress along the net section of the sample (up) and its consequence on the fracture behaviour (down): front and side view. Sample 5B: wire after five drawing passes and notch B with the highest triaxiality level.

Figure 14 shows one representative case of the anisotropic fracture behavior: the sample named 5B (wire of the fifth cold-drawing step and with a notch type B-maximum level of triaxiality). The hoop stress $\sigma_{\theta}$ has a radial distribution (profile) such as that shown in the Figure. Such a distribution, whose maximum net value corresponds to the notch type A and B, maintains the same shape for every value of the annular coordinate $\theta$ in the transverse net section, and reaches a critical value just at the moment associated with the fracture initiation and full propagation.

During these final stages of the fracture test, two things occur: on one hand, the critical value of the Von Mises equivalent stress (characteristic of each steel with independence of the notch type) is reached, and this critical value is the variable governing the fracture process. On the other hand, and corresponding to this final stage too, heavily drawn steels (cold-drawing degree $\geq 3$ ) with a sharp notch type A and B (small notch radius) exhibit the maximum values of the hoop stress $\sigma_{\theta}$, this stress being the variable governing the anisotropic fracture process in this class of samples.

Observing the hoop stress distribution and the result caused by it on the fracture behavior, i.e., on the formation of a vertical fracture step showing a fracture surface consisting of oriented an enlarged cleavage [7] just along the longitudinal cold-drawing direction (wires axis), cf. Figure 15, a question arises about the mechanism of formation of the well-defined vertical fracture step with a $90^{\circ}$ deflection angle. The answer to this question is that such an anisotropic fracture plane is that containing a higher number of fracture initiation points (weakest links) for promoting the catastrophic exfoliation fractures by cleavage parallel to the longitudinal wire axis. 


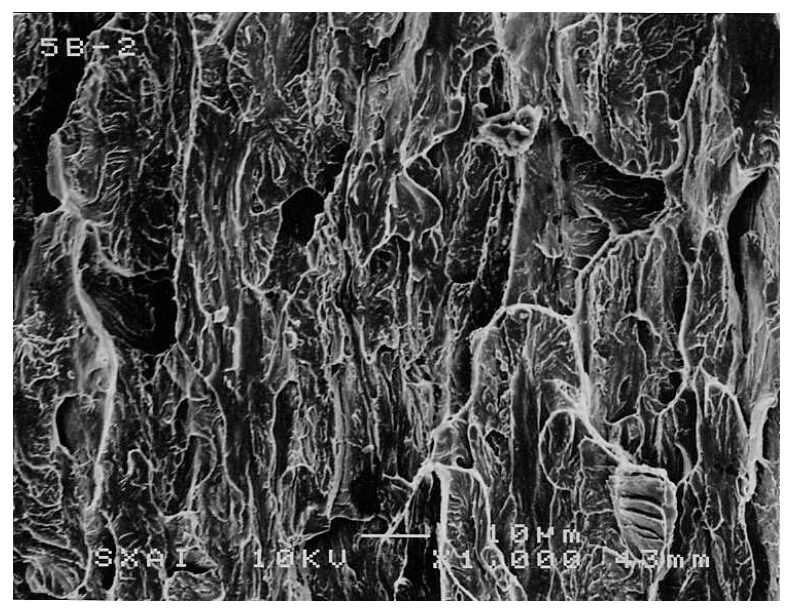

Figure 15. Fracture appearance of the $90^{\circ}$ propagation step: enlarged and oriented cleavage.

The described anisotropic fracture behavior in the most heavily drawn pearlitic steels also appear in the same materials tested using pre-cracked specimens in which the cleavage stress also governs the anisotropic fracture behavior [20].

\section{Conclusions}

Axisymmetric notched cylindrical samples were tested by means of fracture tests until a final fracture. Such samples are a representation of each step of the real manufacture cold-drawing chain and have a circumferentially shaped notch with different values of notch depth and radius, in order to achieve very distinct constraint levels (triaxiality) and fracture behaviors.

With regard to the fracture behavior of the steels with relatively low accumulated plastic strain (cold-drawing degree $<3$ ) and with any notch type $(A, B, C$, and D), they show a fracture surface contained on a transversal plane in the sample net section: isotropic fracture behavior. The same occurs for the steels with a cold-drawing degree $\geq 3$ and blunt notch geometries type $\mathrm{C}$ and $\mathrm{D}$ (higher notch radius).

The steels with relatively high accumulated plastic strain (cold-drawing degree $\geq 3$ ) and with a notch geometry that promotes a higher constraint level-triaxiality (sharp notches A and B) show a fracture surface contained in planes clearly different from those containing the sample net section. In this case, it is possible to observe clear deviations of the fracture path: anisotropic fracture behavior.

With regard to the samples with notch geometry of high radius (blunt notches $C$ and D), they show a $\sigma_{\theta}$ distribution totally increasing from the bottom of the notch until the longitudinal wire axis with total independence of the considered cold-drawn degree.

Sharp notch geometries type A and B (small notch radius) show the higher values of hoop stress for all cold-drawing degrees. The distribution of hoop stress is increasing in the zone closer to the notch up to reaching its maximum value, and then this distribution shows a progressive decrease until the wire axis.

The hoop stress $\sigma_{\theta}$ is proposed as the governing factor of the anisotropic fracture behavior for the case of steels with a high cumulative plastic strain (cold-drawing degree $\geq 3$ ) and maximum triaxiality factor (sharp notches A and B). This hoop stress is called cleavage hoop stress for starting and propagating the cleavage fracture in a direction parallel to the longitudinal wire axis.

Author Contributions: J.T. conceived and designed the research; F.-J.A. performed the tests and the finite element analysis, J.T. and F.-J.A. analyzed the data and wrote the paper. All authors have read and agreed to the published version of the manuscript. 
Funding: This research was funded by the following Spanish institutions: Ministry for Science and Technology (MICYT; Grant MAT2002-01831), Ministry for Education and Science (MEC; Grant BIA2005-08965), Ministry for Science and Innovation (MICINN; Grant BIA2008-06810), Ministry for Economy and Competitiveness (MINECO; Grant BIA2011-27870), Junta de Castilla y León (JCyL; Grants SA067A05, SA111A07, SA039A08 and SA132G18).

Institutional Review Board Statement: Not applicable for studies not involving humans or animals. Informed Consent Statement: Not applicable for studies not involving humans or animals.

Data Availability Statement: The data supporting the study are available on request.

Conflicts of Interest: The authors declare no conflict of interest. The funders had no role in the design of the study; in the collection, analyses, or interpretation of data; in the writing of the manuscript, and in the decision to publish the results.

\section{References}

1. Borchers, C.; Kirchheim, R. Cold-drawn pearlitic steel wires. Prog. Mater. Sci. 2016, 82, 405-444. [CrossRef]

2. Toribio, J. Structural integrity of progressively cold-drawn pearlitic steels: From Raffaello Sanzio to Vincent van Gogh. Procedia Struct. Integr. 2017, 3, 3-10. [CrossRef]

3. Gil-Sevillano, J. Cleavage-limited maximum strength of work-hardened B.C.C. polycrystals. Acta Metall. 1986, $34,1473-1485$.

4. Toribio, J.; Ayaso, F.J. Anisotropic fracture behavior of cold drawn steel: A materials science approach. Mater. Sci. Eng. A 2003, 343, 265-272. [CrossRef]

5. He, Y.; Xiang, S.; Shi, W.; Liu, J.; Ji, X.; Yu, W. Effect of microstructure evolution on anisotropic fracture behaviors of cold drawing pearlitic steels. Mater. Sci. Eng. A 2017, 683, 153-163. [CrossRef]

6. Toribio, J. Anisotropy of hydrogen embrittlement in cold drawn pearlitic steel: A Tribute to Mantegna. Procedia Struct. Integr. 2020, 28, 2438-2443. [CrossRef]

7. Toribio, J.; Ayaso, F.J. Image analysis of exfoliation fracture in cold drawn steel. Mater. Sci. Eng. A 2004, 387-389, 438-441. [CrossRef]

8. Tanaka, M.; Saito, H.; Yasumaru, M.; Higashida, K. Nature of delamination cracks in pearlitic steels. Scripta Mater. 2016, 112, 32-36. [CrossRef]

9. Embury, J.D.; Fisher, R.M. The structure and properties of drawn pearlite. Acta Metall. 1966, 14, 147-159. [CrossRef]

10. Langford, G. Deformation of Pearlite. Metall. Trans. A 1977, 8, 861-875. [CrossRef]

11. Ridley, N. A review of the data on the interlamellar spacing of pearlite. Metall. Trans. A 1984, 15, 1019-1036. [CrossRef]

12. Languillaume, J.; Kapelski, G.; Baudelet, B. Cementite dissolution in heavily cold drawn pearlitic steel wires. Acta Mater. 1997, 45, 1201-1212. [CrossRef]

13. Zelin, M. Microstructure evolution in pearlitic steels during wire drawing. Acta Mater. 2002, 50, 4431-4447. [CrossRef]

14. Hall, E.O. The deformation and ageing of mild steel: III Discussion of results. Proc. Phys. Soc. Sec. B 1951, 64, 747-753. [CrossRef]

15. Petch, N.J. The cleavage strength of polycrystals. J. Iron Steel Inst. 1953, 174, 25-30.

16. Choi, H.C.; Park, K.T. The effect of carbon content on the Hall-Petch parameter in the cold drawn hypereutectoid steels. Scripta Mater. 1996, 34, 857-862. [CrossRef]

17. Nam, W.J.; Bae, C.M.; Lee, C.S. Effect of carbon content on the Hall-Petch parameter in cold drawn pearlitic steel wires. J. Mater Sci. 2002, 37, 2243-2249. [CrossRef]

18. Toribio, J. Relationship between microstructure and strength in eutectoid steels. Mater. Sci. Eng. A 2004, 387-389, 227-230. [CrossRef]

19. Toribio, J.; González, B.; Matos, J.C. Microstructure and mechanical properties in progressively drawn pearlitic steel. Mater. Trans. 2014, 55, 93-98. [CrossRef]

20. Toribio, J.; González, B.; Matos, J.C. Cleavage stress required to produce fracture path deflection in cold-drawn prestressing steel wires. Int. J. Fract. 2007, 144, 189-196. [CrossRef] 